OPEN ACCESS

Edited by:

Graeme R. Polglase,

Monash University, Australia

Reviewed by:

Anup C. Katheria,

Sharp Mary Birch Hospital for Women \& Newborns, United States

Giovanni Vento,

Università Cattolica del Sacro Cuore

*Correspondence:

Georg M. Schmölzer georg.schmoelzer@me.com

Specialty section: This article was submitted to Neonatology,

a section of the journal

Frontiers in Pediatrics

Received: 27 January 2017

Accepted: 19 January 2018

Published: 12 February 2018

Citation:

Baik N, O'Reilly M, Fray C, van Os S,

Cheung P-Y and Schmölzer GM

(2018) Ventilation Strategies during

Neonatal Cardiopulmonary

Resuscitation.

Front. Pediatr. 6:18.

doi: 10.3389/fped.2018.00018

\section{Ventilation Strategies during Neonatal Cardiopulmonary Resuscitation}

\author{
Nariae Baik ${ }^{1,2}$, Megan O’Reilly ${ }^{2,3}$, Caroline Fray',3, Sylvia van Os ${ }^{2,3}$, Po-Yin Cheung ${ }^{2,3}$ and \\ Georg M. Schmölzer ${ }^{2,3 *}$
}

\begin{abstract}
'Department of Pediatrics, Medical University Graz, Graz, Austria, ${ }^{2}$ Centre for the Studies of Asphyxia and Resuscitation, Neonatal Research Unit, Royal Alexandra Hospital, Edmonton, AB, Canada, ${ }^{3}$ Department of Pediatrics, University of Alberta, Edmonton, $A B$, Canada
\end{abstract}

Approximately, 10-20\% of newborns require breathing assistance at birth, which remains the cornerstone of neonatal resuscitation. Fortunately, the need for chest compression (CC) or medications in the delivery room (DR) is rare. About $0.1 \%$ of term infants and up to $15 \%$ of preterm infants receive these interventions, this will result in approximately one million newborn deaths annually worldwide. In addition, CC or medications (epinephrine) are more frequent in the preterm population $(\sim 15 \%)$ due to birth asphyxia. A recent study reported that only 6 per 10,000 infants received epinephrine in the DR. Further, the study reported that infants receiving epinephrine during resuscitation had a high incidence of mortality (41\%) and short-term neurologic morbidity (57\% hypoxic-ischemic encephalopathy and seizures). A recent review of newborns who received prolonged CC and epinephrine but had no signs of life at 10 min following birth noted 83\% mortality, with $93 \%$ of survivors suffering moderate-to-severe disability. The poor prognosis associated with receiving CC alone or with medications in the DR raises questions as to whether improved cardiopulmonary resuscitation methods specifically tailored to the newborn could improve outcomes.

Keywords: infants, newborn, delivery room, neonatal resuscitation, chest compression

\section{INTRODUCTION}

Chest compression (CC) is an infrequent event (0.08\%) in newborns delivered at near-term and term gestation, and happens at higher frequency $(\sim 10 \%)$ in preterm deliveries $(1-5)$. In addition, outcome studies of deliveries requiring resuscitation or CC have reported high rates of mortality and neurodevelopmental impairment in surviving children (1-5). The poor prognosis associated with resuscitation requiring CC alone and/or medications in the delivery room (DR) raises questions as to whether improved cardiopulmonary resuscitation (CPR) techniques specifically tailored toward the newborn infant could improve outcomes.

\section{ASPHYXIA AT BIRTH}

Asphyxia, a condition of impaired gas exchange with simultaneous hypoxia and hypercapnia leading to a mixed metabolic and respiratory acidosis, is the most common reason that newborns fail to make successful transition $(6,7)$. Asphyxia could result from either failure of placental gas exchange before 
delivery (e.g., abruption and chorioamnionitis) or deficient pulmonary gas exchange immediately after birth (e.g., apnea, airway obstruction, and respiratory distress syndrome) (6, 7). Asphyxia depresses myocardial function leading to cardiogenic shock, pulmonary hypertension, mesenteric reperfusion, and acute renal failure. Newborn infants present with serve bradycardic or asystole at birth as a consequence of asphyxia. Current resuscitation guidelines recommend to initiate CC if heart rate remains $<60$ / min despite adequate ventilation with supplementary oxygen for $30 \mathrm{~s}$; CC should be then performed at a rate of $90 / \mathrm{min}$ with 30 ventilations 3:1 C:V (Figure 1A) (8) to achieve adequate oxygen delivery (9-11).

\section{RATIONALE FOR USING 3:1 COMPRESSION TO VENTILATION RATIO}

Neonatal bradycardia or cardiac arrest is caused by hypoxia rather than primary cardiac compromise; therefore, providing ventilation is more beneficial $(9-11)$. However, the optimal $\mathrm{C}: \mathrm{V}$ ratio that should be used during neonatal resuscitation to optimize coronary and cerebral perfusion while providing adequate ventilation of an asphyxiated newborn remains unknown.

Animal studies on cardiac arrest induced by asphyxia in newborn piglets demonstrated that combining CC with ventilations improves ROSC and neurological outcome at $24 \mathrm{~h}$ compared to ventilations or CC alone (12-14). Solevåg et al. performed a study investigating alternating nine $\mathrm{CC}$ and three ventilations in asphyxiated piglets with cardiac arrest with the hypothesis that nine CC would generate higher diastolic blood pressure (15). The time to ROSC was similar between the two approaches (150 and 148 s for 3:1 and 9:3 C:V, respectively). Similarly, C:V ratios of 3:1 and 15:2 were compared using the same model (16). Although the 15:2 C:V ratio provided higher mean CC per minute (75 versus 58 for 3:1), time to ROSC was similar between groups (median time of 195 and $150 \mathrm{~s}$ for 15:2 and 3:1, respectively) (16). These studies suggest that during neonatal $\mathrm{CPR}$, higher $\mathrm{C}: \mathrm{V}$ ratios do not improve outcomes, and potentially a higher ventilation rate is needed.

This is further supported by manikin studies showing higher ventilation rates during simulated CPR using 3:1 C:V compared with higher $\mathrm{C}: \mathrm{V}$ ratios (17-19). A more recent neonatal manikin study examined respiratory parameters during neonatal CPR and reported that a 3:1 C:V ratio delivered significantly higher minute ventilation of $191 \mathrm{~mL} / \mathrm{kg}$ compared to the minute ventilation at 9:3 and 15:2 C:V ratios (140 and $77 \mathrm{~mL} / \mathrm{kg} / \mathrm{min}$, respectively) (20). A further manikin study compared 3:1 C:V with continuous $\mathrm{CC}$ with asynchronous ventilations $(\mathrm{CCaV})$ using $90 \mathrm{CC}$ and 30 non-synchronized inflations and reported significantly higher minute ventilation in the CCaV group compared to the 3:1 group (221 versus $191 \mathrm{~mL} / \mathrm{kg} / \mathrm{min}$, respectively) (21). Schmölzer et al. compared 3:1 C:V CPR with CCaV in a piglet model of neonatal asphyxia and reported similar minute ventilation (387 versus $275 \mathrm{~mL} / \mathrm{kg}$ ) (22). There was also a similar time to ROSC (143 and $114 \mathrm{~s}$ for 3:1 and CCaV, respectively) and survival (3/8 and 6/8, respectively). The same manikin (21) and animal study (22) also reported similar tidal volume $\left(V_{\mathrm{T}}\right)$ delivery between $3: 1 \mathrm{C}: \mathrm{V}$ and
$\mathrm{CCaV}$ [manikin study $V_{\mathrm{T}} 6.4$ and $5.6 \mathrm{~mL} / \mathrm{kg}$ (21), respectively and animal study $V_{\mathrm{T}} 14.7$ versus $11.0 \mathrm{~mL} / \mathrm{kg}$ (22)]. In a secondary analysis of the study by Schmölzer et al. (22), Li et al. reported that during 3:1 C:V a cumulated loss of $V_{\mathrm{T}}$ of $4.5 \mathrm{~mL} / \mathrm{kg}$ occurs for each 3:1 C:V cycle (Figure 2A) (23). Similarly, during CCaV, a cumulated loss of $V_{\mathrm{T}}$ of $9.1 \mathrm{~mL} / \mathrm{kg}$ for each cycle of three CC and one inflation were observed (23). This suggests a potential loss in $V_{\mathrm{T}}$ during CC, which could cause lung derecruitment, hence hamper oxygenation and therefore ROSC. A recent pilot randomized trial in the DR reported that the exhaled $\mathrm{CO}_{2}$ was significantly higher in the $\mathrm{CC}+$ sustained inflation (SI) group with 11 (9) $\mathrm{mmHg}$ compared to $2(1) \mathrm{mmHg}(p<0.001)$ in the $3: 1$ $\mathrm{C}: \mathrm{V}$ ratio group during $\mathrm{CPR}$ suggesting improved gas exchange in the CC + SI group (24). Further, an argument of synchronized $\mathrm{CPR}$ is the potential interference of non-synchronized CC with $V_{\mathrm{T}}$ delivery, resulting in impairment of oxygen delivery. However, the study by Schmölzer et al. observed that 29 and $25 \%$ of manual inflations were similarly affected during $\mathrm{CC}$ using $\mathrm{CCaV}$ or $3: 1$ C:V CPR (22), respectively. These studies suggest that no advantages (e.g., oxygen delivery and $V_{\mathrm{T}}$ or minute ventilation) of using $\mathrm{CCaV}$ compared to $3: 1 \mathrm{C}: \mathrm{V}$.

\section{RATIONAL FOR USING CONTINUOUS CCs WITH SI}

Reoxgenation and adequate blood flow are the cornerstones of neonatal CPR. Any effective resuscitative maneuver should increase blood flow and optimize oxygen delivery. In addition to standard CPR, maneuvers that raise intrathoracic pressure can significantly increase carotid blood flow during CPR. Chandra et al. provided ventilation at a high airway pressure while simultaneously performing CC in an animal model and demonstrated increased carotid flow without compromising oxygenation (25). Further, studies in preterm lambs have demonstrated that an SI also increases intrathoracic pressure without impeding blood flow (26). In the resuscitation of asphyxiated newborn piglets, Schmölzer et al. recently reported that passive ventilation during $\mathrm{CC}$, achieved by superimposing $\mathrm{CC}$ with an SI $(\mathrm{CC}+\mathrm{SI})$ (Figure 1B) (8), significantly improved hemodynamics, minute ventilation, and time to ROSC compared to the current approach of using a 3:1 C:V ratio (mean arterial pressure: 51 versus $31 \mathrm{mmHg}$; pulmonary arterial pressure: 41 versus $31 \mathrm{mmHg}$; mean minute ventilation: 936 versus $623 \mathrm{~mL} / \mathrm{kg}$; and median time to ROSC: 38 versus $143 \mathrm{~s}$, respectively) (8). However, the study by Schmölzer et al. used a CC rate of $120 / \mathrm{min}$ (in the CC + SI group), which is higher than the currently recommended CC rate of 90/ min, which could have also added to the improved outcomes. A recent study using a perinatal cardiac arrest lamb model with transitioning fetal circulation and fluid filled lungs reported that $\mathrm{CC}+\mathrm{SI}$ is as effective as 3:1 C:V ratio in achieving ROSC (27).

\section{Rate of CC}

A recent mathematical model suggests that $\mathrm{CC}$ rates higher than the currently recommended $90 \mathrm{CC} / \mathrm{min}$ could optimize systemic perfusion (28). This model further suggests that the most effective $\mathrm{CC}$ rate depends on body size and weight, which would translate 

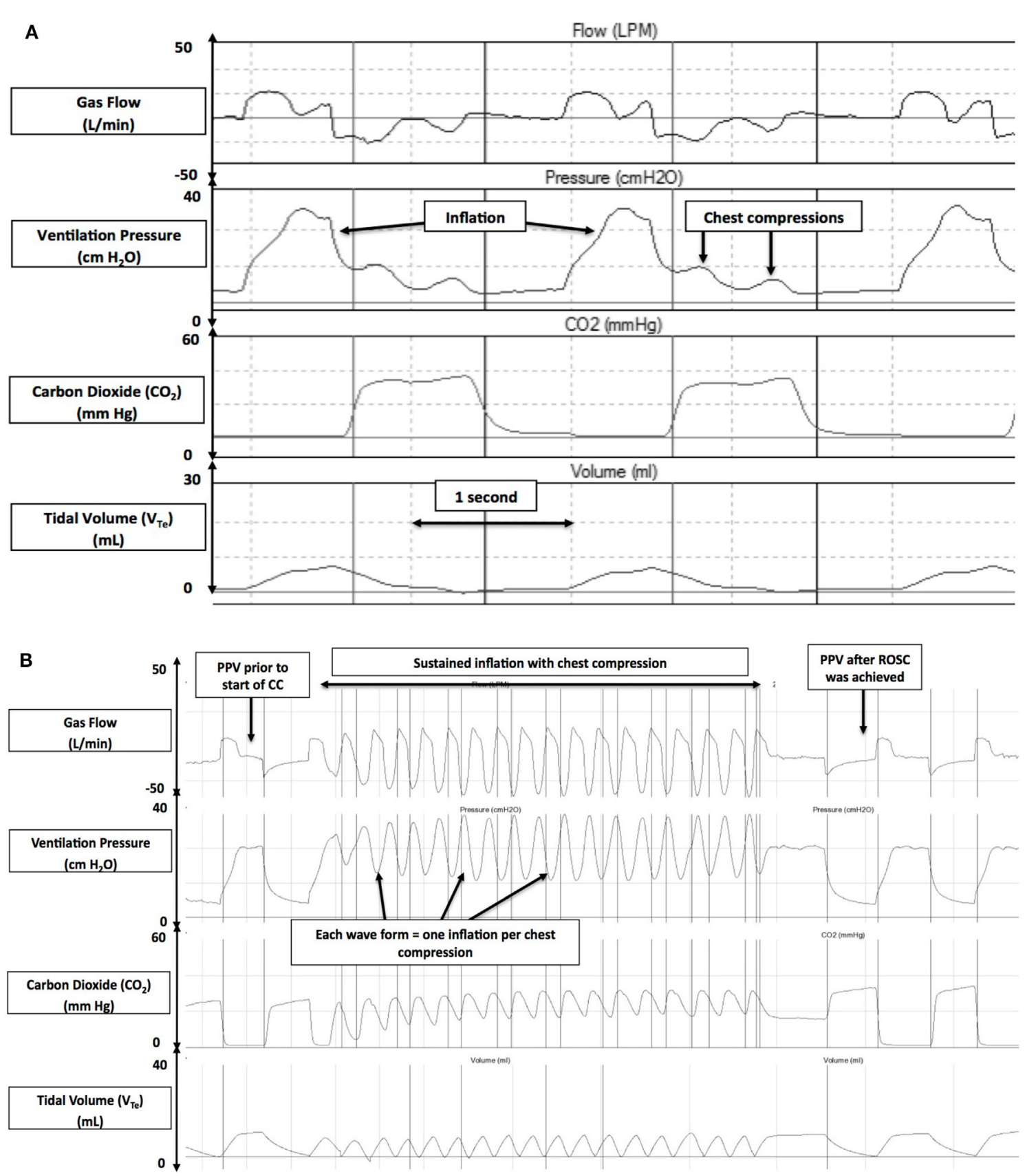

FIGURE 1 | Respiratory waveforms during cardiopulmonary resuscitation in the 3:1 compression:ventilation ratio (3:1 C:V) (A) and chest compression (CC) + sustained inflation (SI) (B) groups (gas flow, airway pressure, $\mathrm{ECO}_{2}$, and tidal volume). Reproduced with permission from Schmölzer et al. (8).

to $180 \mathrm{CC} / \mathrm{min}$ for term infants and even higher rates for preterm infants (28). However, a recent simulation study comparing various CC rates (e.g., 90 versus $120 \mathrm{CC} / \mathrm{min}$ ) reported faster fatigue with increasing CC rates (29). Overall, using CC rates of 90 CC/ min was the least fatiguing and the most preferred method of neonatal CPR compared to that using $120 \mathrm{CC} / \mathrm{min}$ (29). This is further supported by a study by Solevåg et al. who quantified the force used during $\mathrm{CC}$ and reported fatigue occurring faster with increasing CC rates (30). These studies suggest that a rate of $90 \mathrm{CC} / \mathrm{min}$ would be the least fatiguing rate. Further, a recent randomized animal trial compared CC + SI using CC rates of 90 versus $120 \mathrm{CC} / \mathrm{min}$ and reported similar time of ROSC, survival rates, and respiratory parameters during CPR (31). During $\mathrm{CC}$, carotid blood flow, mean arterial pressure, and percentage change in ejection fraction and cardiac output were higher in the CC + SI 90/min group compared to CC + SI 120/min (31). This further supports that higher CC rates do not improve systemic perfusion and that the current recommendation of $90 \mathrm{CC} / \mathrm{min}$ 

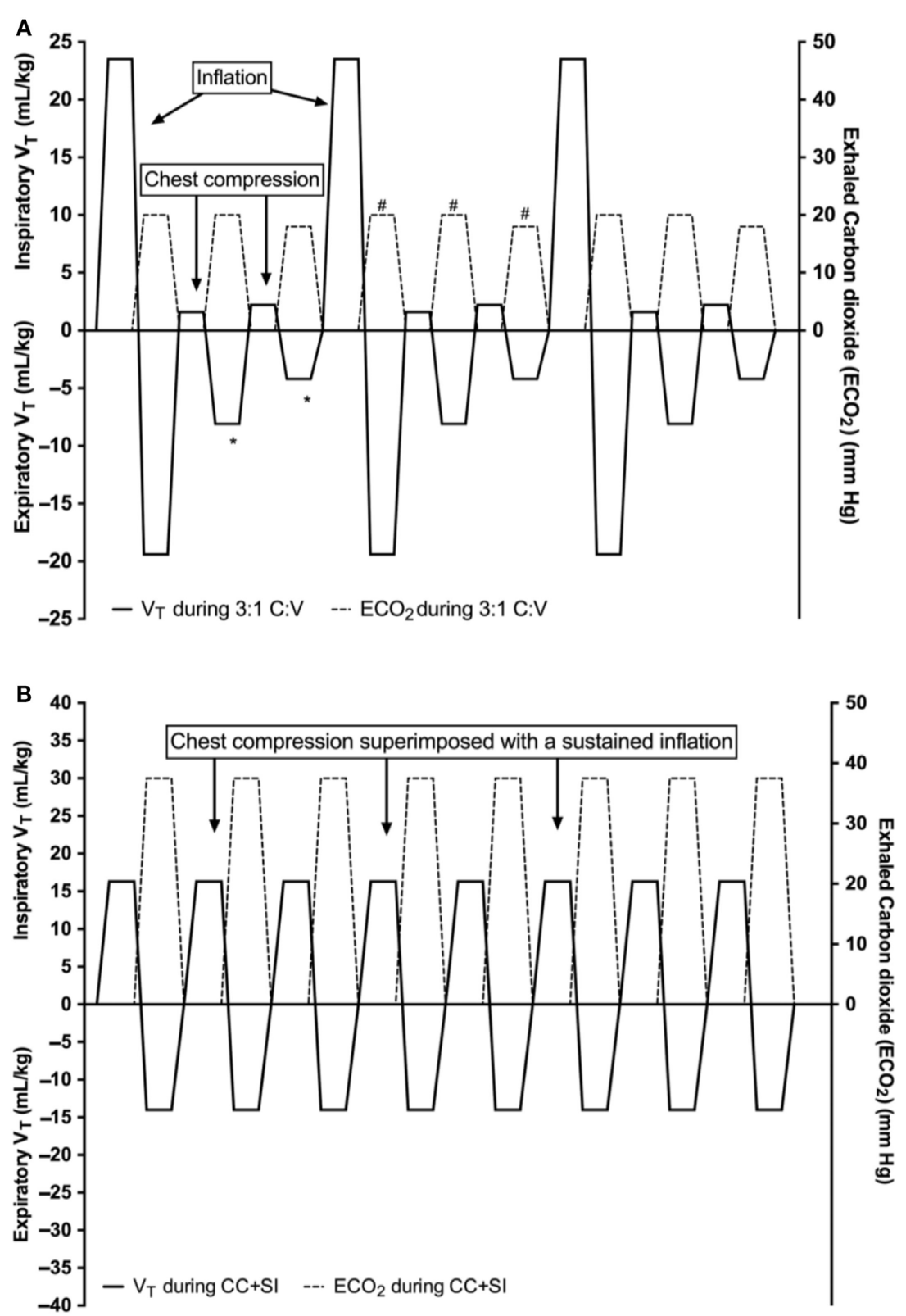

FIGURE 2 | Tidal volume (mL/kg) changes during 3:1 compression:ventilation ratio (3:1 C:V) (A) and continuous chest compressions (CCs) superimposed by sustained inflations (SIs) (CC + SI) (B). Reproduced with permission from Li et al. (23).

are sufficient to achieve systemic perfusion. This is further supported by a randomized animal trial comparing $\mathrm{CC}+\mathrm{SI}$ using a rate of $90 / \mathrm{min}$ with $3: 1 \mathrm{C}: \mathrm{V}$. CC + SI significantly reduced the median (IQR) time of ROSC, i.e., $34 \mathrm{~s}(28-156 \mathrm{~s})$ versus $210 \mathrm{~s}$ $(72-300 \mathrm{~s})$ in the $3: 1$ group $(p=0.048)$. CC + SI also significantly reduced the requirement for $100 \%$ oxygen, improved respiratory parameters, and resulted in a similar hemodynamic recovery (32). Furthermore, the study reported no significant differences in the concentrations of interleukin (IL) IL-1 $\beta$, IL-6, IL-8, or tumor necrosis factor in lung tissue homogenates (32). This suggests that SI does not increase the risk of brain injury as recently suggested in two meta-analyses $(33,34)$.

\section{Adequate Ventilation during CC}

Providing adequate ventilation to achieve reoxgenation is a cornerstone of neonatal CPR. Current best practice is to provide $90 \mathrm{CC}$ and 30 ventilations that are coordinated during a pause (9). The purpose of inflations during CC is to deliver an adequate $V_{\mathrm{T}}$ to facilitate gas exchange. However, delivery of an adequate $V_{\mathrm{T}}$ during CPR remains difficult. Several DR studies reported that mask ventilation is the most difficult task during neonatal CPR. $V_{\mathrm{T}}$ delivery could be compromised due to mask leak or airway obstruction (35-43), causing inadequate oxygen delivery to any asphyxiated newborn. A recent case by Li et al. reported a large mask leak during mask ventilation in 
the DR, which resulted in severe bradycardia and the need for neonatal CC (44). In addition, once CC was started, mask leak further increased (44). This is further supported by manikin studies, which reported decreased expiratory $V_{\mathrm{T}}$ once CC were started $(20,45,46)$. Binder-Heschl et al. examined human or monitor feedback during simulated neonatal CPR using a leakfree manikin and reported lower expiratory $V_{\mathrm{T}}$ in all groups compared with mask ventilation alone (46). These studies suggest a decrease in expiratory $V_{\mathrm{T}}$ once CCs are initiated. A loss in expiratory $V_{\mathrm{T}}$ could cause lung derecruitment, which could hamper oxygenation and therefore ROSC. This has been recently confirmed in an animal model of neonatal CPR. In a secondary analysis of the study by Schmölzer et al. (22), Li et al. reported that during a significant loss of expiratory $V_{\mathrm{T}}$ compared to inspiratory $V_{\mathrm{T}}$ over each $3: 1 \mathrm{C}: \mathrm{V}$ cycle (mean total inspiratory $V_{\mathrm{T}}$ was $27.2 \mathrm{~mL} / \mathrm{kg}$ and mean total expiratory $V_{\mathrm{T}}$ $31.7 \mathrm{~mL} / \mathrm{kg}=$ a loss of $4.5 \mathrm{~mL} / \mathrm{kg}$ per 3:1 C:V cycle) (Figure 2A) $(8,23)$. In contrast, no $V_{\mathrm{T}}$ loss was observed in CC + SI. Instead, continuous lung recruitment and establishment of functional residual capacity were observed (mean total inspired $V_{\mathrm{T}}$ was $16.3 \mathrm{~mL} / \mathrm{kg}$ and mean total expiratory was $14 \mathrm{~mL} / \mathrm{kg}=$ a gain of $2.3 \mathrm{~mL} / \mathrm{kg} / \mathrm{CC}+$ SI cycle) (Figure 2B) $(8,23)$. This improvement in $V_{\mathrm{T}}$ delivery might lead to better alveolar oxygen delivery and lung aeration. More importantly, the initial study by Schmölzer et al. (22) and secondary analysis by Li et al. (23) describe passive $V_{\mathrm{T}}$ delivery during each CC cycle. Similar observations have been reported by Tsui et al. (47) in children under the age of 17 years undergoing any surgery requiring general anesthesia and endotracheal intubation. Tsui et al. compared $V_{\mathrm{T}}$ after induction of general anesthesia before and after intubation by applying a downward force on the chest, which was not greater than the patient's weight in seven infants (47). Overall, median (IQR) $V_{\mathrm{T}}$ generated before and after intubation was $2.4(0.8-4.0)$ and $2.0(0.4-3.6) \mathrm{mL} / \mathrm{kg}$, respectively (47). Although, Tsui et al. only applied gentle chest pressure, they could achieve $~ 33 \%$ of an infant's physiological $V_{\mathrm{T}}$ of $5-7 \mathrm{~mL} / \mathrm{kg}$. During CC, the mean applied forced is $\sim 10 \mathrm{~kg}$ (3-4 times the weight of the newborn infant) (30), which would result in adequate $V_{\mathrm{T}}$ delivery during CC + SI. Further, Solevåg et al. determined the distending pressure needed to achieve sufficient $V_{\mathrm{T}}$ delivery using different models (manikin and cadaver piglets) during $\mathrm{CC}+\mathrm{SI}$ (48). Distending pressure and $V_{\mathrm{T}}$ correlated in cadaver piglets $(r=0.83, p<0.001)$, manikin $(r=0.98, p<0.001)$, and combined data $(r=0.49, p<0.001)$. $V_{\mathrm{T}}$ was delivered during chest recoil during $\mathrm{CC}$ in both models. In cadaver piglets, a distending pressure $\sim 25 \mathrm{cmH}_{2} \mathrm{O}$ was needed to achieve an adequate $V_{\text {T. This }}$ study suggests that chest recoil generates $V_{\mathrm{T}}$ depending on an adequate distending pressure, and that a pressure of $\sim 25 \mathrm{cmH}_{2} \mathrm{O}$ will be needed to achieve adequate $V_{\mathrm{T}}$ delivery. In addition, this has been recently shown in the first randomized controlled trial in the DR by Schmölzer et al. (24). Overall, the mean (SD) time to ROSC was significantly shorter in the CC + SI group with 31 (9) s compared with 138 (72) $s$ in the 3:1 C:V group $(p=0.011)$. Infants in the CC + SI group had significantly higher respiratory rates with 91 (1) versus 29 (2) inflations/min in the $3: 1 \mathrm{C}: \mathrm{V}$ group $(p=0.0001)$. The delivered tidal volume ranged between 0.6 and $4.4 \mathrm{~mL} / \mathrm{kg}$ in the CC + SI group and 0.8 and $4.5 \mathrm{~mL} / \mathrm{kg}$ in the 3:1 C:V group. Median (IQR) minute ventilation was significantly higher in the SI + CC group compared to the 3:1 C:V group $165(85-216)$ versus $101(48-110) \mathrm{mL} / \mathrm{kg} / \mathrm{min}$ $(p=0.0001)$. This is currently further studied in a multicenter cluster randomized trial "CC + SI versus 3:1 C:V ratio during neonatal CPR (SURV1VE)-NCT02858583” to study this in a larger patient population.

\section{QUALITY AND DEPTH OF CC AND/OR THE ADMINISTRATION OF EPINEPHRINE}

Improved left ventricular ejection fraction have been postulated after review of computer tomography images of neonates when CC with a $1 / 3$ anterior-posterior chest diameter was compared with a $1 / 4$ anterior-posterior chest diameter (49). The current neonatal resuscitation guidelines recommend a $1 / 3$ anterior-posterior chest diameter during CPR (9-11). Adequate CC depth is important to optimize cardiac output. However, compressing to deep could cause rib fractures, cardiac contusion, and other thoracic injuries (7). While compressing to shallow might not create the required cardiac output or diastolic blood pressure (50, 51). A retrospective review of six infants (2 weeks to 7.3 months old) with indwelling arterial blood pressure monitoring reported that CC with a $1 / 2$ anterior-posterior chest diameter produced significantly higher systolic blood pressure but similar diastolic blood pressure compared with CC using a 1/3 anterior-posterior chest diameter. However, the optimal CC depth has not been rigorously evaluated in neonates. Furthermore, no study has examined tidal volume delivery with different anterior-posterior chest diameter.

\section{CONCLUSION}

Successful resuscitation from cardiac arrest or severe bradycardia requires the delivery of high-quality $\mathrm{CC}$ while providing adequate ventilation. However, until now, no study has examined different CC techniques during neonatal resuscitation in asphyxiated newborn infants, and randomized controlled trials are urgently needed.

\section{AUTHOR CONTRIBUTIONS}

Concept, literature search, review of the data, writing of the manuscript, and review of the manuscript: $\mathrm{NB}, \mathrm{MO}, \mathrm{CF}, \mathrm{SO}$, P-YC, and GS.

\section{FUNDING}

GS is a recipient of the Heart and Stroke Foundation/University of Alberta Professorship of Neonatal Resuscitation and Heart and Stroke Foundation Canada and Heart and Stroke Foundation Alberta New Investigator Award. This research has been facilitated by the Women and Children's Health Research Institute through the generous support of the Stollery Children's Hospital Foundation. 


\section{REFERENCES}

1. Handley SC, Sun Y, Wyckoff MH, Lee HC. Outcomes of extremely preterm infants after delivery room cardiopulmonary resuscitation in a population-based cohort. J Perinatol (2015) 35:379-83. doi:10.1038/ jp.2014.222

2. Wyckoff MH, Salhab WA, Heyne RJ, Kendrick DE, Stoll B, Laptook AR, et al. Outcome of extremely low birth weight infants who received delivery room cardiopulmonary resuscitation. J Pediatr (2012) 160:239-44.e2. doi:10.1016/j. jpeds.2011.07.041

3. Shah PS, Tai KFY. Chest compression and/or epinephrine at birth for preterm infants $<32$ weeks gestational age: matched cohort study of neonatal outcomes. J Perinatol (2009) 29:693-7. doi:10.1038/jp.2009.70

4. Shah PS. Extensive cardiopulmonary resuscitation for VLBW and ELBW infants: a systematic review and meta-analyses. J Perinatol (2009) 29:655-61. doi:10.1038/jp.2009.71

5. Wyckoff MH, Perlman JM. Cardiopulmonary resuscitation in very low birth weight infants. Pediatrics (2000) 106:618-20. doi:10.1542/peds.106.3.618

6. Kapadia V, Wyckoff MH. Chest compressions for bradycardia or asystole in neonates. Clin Perinatol (2012) 39:833-42. doi:10.1016/j.clp.2012.09.011

7. Solevåg AL, Cheung P-Y, O’Reilly M, Schmölzer GM. A review of approaches to optimise chest compressions in the resuscitation of asphyxiated newborns. Arch Dis Child Fetal Neonatal Ed (2016) 101:F272-6. doi:10.1136/ archdischild-2015-309761

8. Schmölzer GM, O'Reilly M, LaBossiere J, Lee T-F, Cowan S, Qin S, et al. Cardiopulmonary resuscitation with chest compressions during sustained inflations: a new technique of neonatal resuscitation that improves recovery and survival in a neonatal porcine model. Circulation (2013) 128:2495-503. doi:10.1161/CIRCULATIONAHA.113.002289

9. Perlman JM, Wyllie JP, Kattwinkel J, Wyckoff MH, Aziz K, Guinsburg R, et al. Part 7: Neonatal resuscitation: 2015 International Consensus on Cardiopulmonary Resuscitation and Emergency Cardiovascular Care Science with Treatment Recommendations. Circulation (2015) 132:S204-41. doi:10.1161/CIR.0000000000000276

10. Wyckoff MH, Aziz K, Escobedo MB, Kattwinkel J, Perlman JM, Simon WM, et al. Part 13: Neonatal resuscitation: 2015 American Heart Association Guidelines Update for Cardiopulmonary Resuscitation and Emergency Cardiovascular Care. Circulation (2015) 132:S543-60. doi:10.1161/ CIR.0000000000000267

11. Wyllie J, Perlman JM, Kattwinkel J, Wyckoff MH, Aziz K, Guinsburg R, et al. Part 7: Neonatal resuscitation: 2015 International Consensus on Cardiopulmonary Resuscitation and Emergency Cardiovascular Care Science with Treatment Recommendations. Resuscitation (2015) 95:e169-201. doi:10.1016/j.resuscitation.2015.07.045

12. Berg RA, Sanders AB, Kern KB, Hilwig RW, Heidenreich JW, Porter ME, et al. Adverse hemodynamic effects of interrupting chest compressions for rescue breathing during cardiopulmonary resuscitation for ventricular fibrillation cardiac arrest. Circulation (2001) 104:2465-70. doi:10.1161/hc4501. 098926

13. Berg RA, Kern KB, Sanders AB, Otto CW, Hilwig RW, Ewy GA. Bystander cardiopulmonary resuscitation. Is ventilation necessary? Circulation (1993) 88:1907-15. doi:10.1161/01.CIR.88.4.1907

14. Berg RA, Hilwig RW, Kern KB, Ewy GA. "Bystander" chest compressions and assisted ventilation independently improve outcome from piglet asphyxial pulseless "cardiac arrest". Circulation (2000) 101:1743-8. doi:10.1161/01. CIR.101.14.1743

15. Solevåg AL, Dannevig I, Wyckoff MH, Saugstad OD, Nakstad B. Extended series of cardiac compressions during CPR in a swine model of perinatal asphyxia. Resuscitation (2010) 81:1571-6. doi:10.1016/j.resuscitation.2010.06.007

16. Solevåg AL, Dannevig I, Wyckoff MH, Saugstad OD, Nakstad B. Return of spontaneous circulation with a compression:ventilation ratio of 15:2 versus 3:1 in newborn pigs with cardiac arrest due to asphyxia. Arch Dis Child Fetal Neonatal Ed (2011) 96:F417-21. doi:10.1136/adc.2010.200386

17. Hemway RJ, Christman C, Perlman JM. The $3: 1$ is superior to a $15: 2$ ratio in a newborn manikin model in terms of quality of chest compressions and number of ventilations. Arch Dis Child Fetal Neonatal Ed (2013) 98:F42-5. doi:10.1136/archdischild-2011-301334

18. Srikantan SK, Berg RA, Cox T, Tice L, Nadkarni V. Effect of one-rescuer compression/ventilation ratios on cardiopulmonary resuscitation in infant, pediatric, and adult manikins. Pediatr Crit Care Med (2005) 6:293-7. doi:10.1097/01.PCC.0000161621.74554.15

19. Whyte SD, Sinha AK, Wyllie JP. Neonatal resuscitation - a practical assessment. Resuscitation (1999) 40:21-5. doi:10.1016/S0300-9572(98)00143-9

20. Solevåg AL, Madland JM, Gjaerum E, Nakstad B. Minute ventilation at different compression to ventilation ratios, different ventilation rates, and continuous chest compressions with asynchronous ventilation in a newborn manikin. Scand J Trauma Resusc Emerg Med (2012) 20:73. doi:10.1186/1757-7241-20-73

21. Boldingh AM, Solevåg AL, Aasen E, Nakstad B. Resuscitators who compared four simulated infant cardiopulmonary resuscitation methods favoured the three-to-one compression-to-ventilation ratio. Acta Paediatr (2016) 105:910-6. doi:10.1111/apa.13339

22. Schmölzer GM, O’Reilly M, LaBossiere J, Lee T-F, Cowan S, Nicoll J, et al. 3:1 compression to ventilation ratio versus continuous chest compression with asynchronous ventilation in a porcine model of neonatal resuscitation. Resuscitation (2014) 85:270-5. doi:10.1016/j.resuscitation.2013.10.011

23. Li ES-S, Cheung P-Y, O’Reilly M, Schmölzer GM. Change in tidal volume during cardiopulmonary resuscitation in newborn piglets. Arch Dis Child Fetal Neonatal Ed (2015) 100:F530-3. doi:10.1136/archdischild-2015-308363

24. Schmölzer GM, O'Reilly M, Fray C, van Os S, Cheung P-Y. Chest compression during sustained inflation versus 3:1 chest compression:ventilation ratio during neonatal cardiopulmonary resuscitation: a randomised feasibility trial. Arch Dis Child Fetal Neonatal Ed (2017). doi:10.1136/archdischild-2017313037

25. Chandra N, Rudikoff M, Weisfeldt M. Simultaneous chest compression and ventilation at high airway pressure during cardiopulmonary resuscitation. Lancet (1980) 315:175-8. doi:10.1016/S0140-6736(80)90662-5

26. Sobotka K, Hooper SB, Allison BJ, Pas te A, Davis PG, Morley CJ, et al. An initial sustained inflation improves the respiratory and cardiovascular transition at birth in preterm lambs. Pediatr Res (2011) 70:56-60. doi:10.1203/ PDR.0b013e31821d06a1

27. Vali P, Chandrasekharan P, Rawat M, Gugino S, Koenigsknecht C, Helman J, et al. Continuous chest compressions during sustained inflations in a perinatal asphyxial cardiac arrest lamb model. Pediatr Crit Care Med (2017) 18:e370-7. doi:10.1097/PCC. 0000000000001248

28. Babbs C, Meyer A, Nadkarni V. Neonatal CPR: room at the top - a mathematical study of optimal chest compression frequency versus body size. Resuscitation (2009) 80:1280-4. doi:10.1016/j.resuscitation.2009.07.014

29. Li ES-S, Cheung P-Y, O’Reilly M, Aziz K, Schmölzer GM. Rescuer fatigue during simulated neonatal cardiopulmonary resuscitation. J Perinatol (2015) 35:142-5. doi:10.1038/jp.2014.165

30. Solevåg AL, Cheung P-Y, Li ES-S, Aziz K, O’Reilly M, Fu B, et al. Quantifying force application to a newborn manikin during simulated cardiopulmonary resuscitation. J Matern Fetal Neonatal Med (2016) 29:1770-2. doi:10.3109/14 767058.2015.1061498

31. Li ES-S, Cheung P-Y, Lee T-F, Lu M, O’Reilly M, Schmölzer GM. Return of spontaneous circulation is not affected by different chest compression rates superimposed with sustained inflations during cardiopulmonary resuscitation in newborn piglets. PLoS One (2016) 11:e0157249. doi:10.1371/journal. pone. 0157249

32. Li ES-S, Görens I, Cheung P-Y, Lee T-F, Lu M, O'Reilly M, et al. Chest compressions during sustained inflations improve recovery when compared to a 3:1 compression:ventilation ratio during cardiopulmonary resuscitation in a neonatal porcine model of asphyxia. Neonatology (2017) 112:337-46. doi:10.1159/000477998

33. Bruschettini M, O’Donnell CPF, Davis PG, Morley CJ, Moja L, Zappettini S, et al. Sustained versus standard inflations during neonatal resuscitation to prevent mortality and improve respiratory outcomes. Cochrane Database Syst Rev (2017) 11:1273-6. doi:10.1002/14651858.CD004953.pub3

34. Schmölzer GM, Kumar M, Aziz K, Pichler G, O’Reilly M, Lista G, et al. Sustained inflation versus positive pressure ventilation at birth: a systematic review and meta-analysis. Arch Dis Child Fetal Neonatal Ed (2015) 100:F361-8. doi:10.1136/archdischild-2014-306836

35. Schmölzer GM, Dawson JA, Kamlin COF, O'Donnell CPF, Morley CJ, Davis PG. Airway obstruction and gas leak during mask ventilation of preterm infants in the delivery room. Arch Dis Child Fetal Neonatal Ed (2011) 96:F254-7. doi:10.1136/adc.2010.191171

36. Schmölzer GM, Kamlin COF, O’Donnell CPF, Dawson JA, Morley CJ, Davis PG. Assessment of tidal volume and gas leak during mask ventilation of 
preterm infants in the delivery room. Arch Dis Child Fetal Neonatal Ed (2010) 95:F393-7. doi:10.1136/adc.2009.174003

37. Poulton DA, Schmölzer GM, Morley CJ, Davis PG. Assessment of chest rise during mask ventilation of preterm infants in the delivery room. Resuscitation (2011) 82:175-9. doi:10.1016/j.resuscitation.2010.10.012

38. Finer N, Rich W, Wang CL, Leone TA. Airway obstruction during mask ventilation of very low birth weight infants during neonatal resuscitation. Pediatrics (2009) 123:865-9. doi:10.1542/peds.2008-0560

39. Schilleman K, van der Pot CJM, Hooper SB, Lopriore E, Walther FJ, Pas te A. Evaluating manual inflations and breathing during mask ventilation in preterm infants at birth. J Pediatr (2013) 162:457-63. doi:10.1016/j.jpeds.2012.09.036

40. Cheung D, Mian QN, Cheung P-Y, O’Reilly M, Aziz K, van Os S, et al. Mask ventilation with two different face masks in the delivery room for preterm infants: a randomized controlled trial. J Perinatol (2015) 35:1-5. doi:10.1038/ jp. 2015.8

41. Dawson JA, Schmölzer GM, Kamlin COF, Pas te A, O'Donnell CPF, Donath $S$, et al. Oxygenation with T-piece versus self-inflating bag for ventilation of extremely preterm infants at birth: a randomized controlled trial. J Pediatr (2011) 158:912-8.e1-2. doi:10.1016/j.jpeds.2010.12.003

42. Schmölzer GM, Kamlin COF, Dawson JA, Pas te A, Morley CJ, Davis PG. Respiratory monitoring of neonatal resuscitation. Arch Dis Child Fetal Neonatal Ed (2010) 95:F295-303. doi:10.1136/adc.2009.165878

43. van Os S, Cheung P-Y, Pichler G, Aziz K, O’Reilly M, Schmölzer GM. Exhaled carbon dioxide can be used to guide respiratory support in the delivery room. Acta Paediatr (2014) 103:796-806. doi:10.1111/apa.12650

44. Li ES-S, Cheung P-Y, Pichler G, Aziz K, Schmölzer GM. Respiratory function and near infrared spectroscopy recording during cardiopulmonary resuscitation in an extremely preterm newborn. Neonatology (2014) 105:200-4. doi:10.1159/000357609

45. Roehr C-C, Schmölzer GM, Thio M, Dawson JA, Dold SK, Schmalisch G, et al. How ABBA may help improve neonatal resuscitation training: auditory prompts to enable coordination of manual inflations and chest compressions. J Paediatr Child Health (2014) 50:444-8. doi:10.1111/jpc.12507
46. Binder-Heschl C, Schmölzer GM, O’Reilly M, Schwaberger B, Pichler G. Human or monitor feedback to improve mask ventilation during simulated neonatal cardiopulmonary resuscitation. Arch Dis Child Fetal Neonatal Ed (2014) 99:F120-3. doi:10.1136/archdischild-2013-304311

47. Tsui BCH, Horne S, Tsui J, Corry GN. Generation of tidal volume via gentle chest pressure in children over one year old. Resuscitation (2015) 92:148-53. doi:10.1016/j.resuscitation.2015.02.021

48. Solevåg AL, Lee TF, Lu M, Schmölzer GM, Cheung P-Y. Tidal volume delivery during continuous chest compressions and sustained inflation. Arch Dis Child Fetal Neonatal Ed (2017) 102:F85-7. doi:10.1136/archdischild-2016311043

49. Meyer A, Nadkarni V, Pollock A, Babbs C, Nishisaki A, Braga M, et al. Evaluation of the Neonatal Resuscitation Program's recommended chest compression depth using computerized tomography imaging. Resuscitation (2010) 81:544-8. doi:10.1016/j.resuscitation.2010.01.032

50. Maher KO, Berg RA, Lindsey CW, Simsic J, Mahle WT. Depth of sternal compression and intra-arterial blood pressure during CPR in infants following cardiac surgery. Resuscitation (2009) 80:662-4. doi:10.1016/j. resuscitation.2009.03.016

51. Wyckoff MH. Neonatal cardiopulmonary resuscitation: critical hemodynamics. NeoReviews (2010) 11:e123-9. doi:10.1542/neo.11-3-e123

Conflict of Interest Statement: The authors declare that the research was conducted in the absence of any commercial or financial relationships that could be construed as a potential conflict of interest.

Copyright $\odot 2018$ Baik, O'Reilly, Fray, van Os, Cheung and Schmölzer. This is an open-access article distributed under the terms of the Creative Commons Attribution License (CC BY). The use, distribution or reproduction in other forums is permitted, provided the original author(s) and the copyright owner are credited and that the original publication in this journal is cited, in accordance with accepted academic practice. No use, distribution or reproduction is permitted which does not comply with these terms. 